\title{
Editorial
}

\section{Eucalyptus beyond Its Native Range: Environmental Issues in Exotic Bioenergy Plantations}

\author{
John A. Stanturf, ${ }^{1}$ Eric D. Vance, ${ }^{2}$ Thomas R. Fox, ${ }^{3}$ and Matias Kirst ${ }^{4}$ \\ ${ }^{1}$ Center for Forest Disturbance Science, USDA Forest Service, Southern Research Station, Athens, GA 30602, USA \\ ${ }^{2}$ National Council for Air and Stream Improvement, Research Triangle Park, NC 27709, USA \\ ${ }^{3}$ Virginia Polytechnic Institute and State University, Blacksburg, VA 24061, USA \\ ${ }^{4}$ University of Florida, Gainesville, FL 32611, USA
}

Correspondence should be addressed to John A. Stanturf; drdirt48@gmail.com

Received 12 March 2013; Accepted 12 March 2013

Copyright (C) 2013 John A. Stanturf et al. This is an open access article distributed under the Creative Commons Attribution License, which permits unrestricted use, distribution, and reproduction in any medium, provided the original work is properly cited.

The genus Eucalyptus is native to Australia and Indonesia but has been widely planted in many countries. Eucalyptus has proven to be particularly successful in tropical and subtropical regions. Several species are also successful in some temperate regions, but problems with sudden and severe frosts pose limitations. Current plantations around the world are dominated by the "big nine" species (E. camaldulensis, E. grandis, E. tereticornis, E. globulus, E. nitens, E. urophylla, E. saligna, E. dunnii, and E. pellita) and their hybrids, which together account for more than $90 \%$ of Eucalyptus planted forests. Much of current tree improvement efforts focus on the use of hybrids and clones, and development of genetically modified Eucalyptus is already underway.

For many reasons, there is increased interest in using wood for energy, and short-rotation plantings of Eucalyptus will likely be an important source of feedstock [1]. Many Eucalyptus species have desirable properties for bioenergy plantations, including rapid growth rates and high wood density. The indeterminant growth pattern and evergreen foliage allow eucalypts to grow whenever climatic conditions are suitable. The sclerophyllous leaves of eucalypts allow them to withstand very dry conditions and may also be an adaptation to low nutrient conditions. However, the same traits that make Eucalyptus attractive for bioenergy and other bioproducts, such as rapid growth, high fecundity, and tolerance of a wide range of climatic and soil conditions, also make them potentially invasive.
The prospect of widespread planting of these nonnative species for commercial purposes in the southern United States has again arisen, prompting questions about potential environmental effects. In response, a conference was held in Charleston, South Carolina, in February of 2012 to review the history of Eucalyptus research and culture in the USA and around the world and to examine potential environmental issues surrounding their expanded introduction in the southern USA. Environmental issues addressed included invasiveness potential, fire risk, water use, and sustainability. Papers from that conference, as well as contributions from other countries that shed light on these issues, are the subject of this special issue.

Background. Two papers in this special issue summarize the history of Eucalyptus plantings in the USA. R. C. Kellison et al. discuss the introduction of Eucalyptus species to the United States while D. L. Rockwood reviews the history and status of tree improvement research activities with E. grandis, E. robusta, E. camaldulensis, E. tereticornis, E. amplifolia, and Corymbia torelliana in Florida. Significant plantings of Eucalyptus in the United States began with introductions from Australia as a result of the California Gold Rush in 1849. Eucalyptus species were introduced in the southern USA as early as 1878 , but no significant commercial plantations were established until the late 1960s. Performance of selected species for ornamental purposes caught the attention of 
forest industry and led to species-introduction trials in 1959. Cooperative efforts by forest industry and the USDA Forest Service on genetic improvement of selected species for fiber production were successful enough to engender interest from industrial forestry companies in the upper South, who established plantations with little attention paid to species or seed source. These plantings failed, leading to more systematic evaluation of 569 sources representing 103 species over a 14-year period by the Hardwood Research Cooperative at North Carolina State University. Severe winter temperatures in late 1983 and early 1984 and 1985 terminated this effort. Research to develop frost-tolerant Eucalyptus in other regions of the world combined with moderated temperatures across the South has fueled renewed efforts to identify frost-tolerant species adapted to this region.

Even in Florida, low temperatures are a challenge. Three 100 -year freezes in the 1980s, extended cold periods during the winter of 2010-11, and the abrupt freezes of the "warm" winter of 2011-12 affected survival and growth of even frosttolerant young eucalypts. A renewed effort to identify frosttolerant species and genetic modifications to increase frosttolerance that will permit expansion of the range of Eucalyptus is driven by the potential need for 20 million $\mathrm{Mg} \mathrm{yr}^{-1}$ of Eucalyptus wood for pulp and biofuel production in the southern USA by 2022 [1]. If appropriate species and geno-

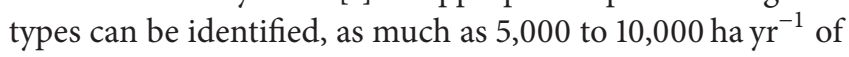
commercial Eucalyptus plantations may be established in the South, most likely in the Lower Coastal Plain region of north Florida, Georgia, Alabama, Mississippi, Louisiana, and Texas [2]. Given the current effort to develop Eucalyptus clones that tolerate the weather extremes of the South, the question may not be "Should we plant Eucalyptus?", but instead "How should we manage Eucalyptus plantations?"

The potential productivity of Eucalyptus under short rotation for biomass is significantly greater than the widely cultured Pinus species [3-5]. Short-rotation systems in Peninsular Florida using E. grandis and E. amplifolia can produce up to 67 green $\mathrm{Mg} \mathrm{ha}^{-1} \mathrm{yr}^{-1}$ in multiple rotations as short as three years. Nevertheless, high silvicultural costs associated with establishment and management may be a barrier to Eucalyptus production in the USA. Based on experience with Eucalyptus management gained from the earlier work, Kellison et al. suggest the following emphases: concentrate efforts on soils of sandy clay loam and clay loam textures and avoid soils with imperfect or excessive drainage; keep plantations free from weed competition for at least the first two growing seasons; and develop efficient fertilizer treatments. Seedling quality for bareroot planting should have rootshoot ratios in the range of 0.6 , and seedlings should be planted in early spring, but after the last frost. Container seedlings can be planted whenever there is adequate soil moisture but should be done early enough for adequate growth before frosts. With the development of proven clones, economical and rapid propagation becomes a need, with current vegetative propagules about $33 \%$ more expensive than seedlings. Weed control treatments are not well developed for Eucalyptus in the South and may be the greatest silvicultural challenge. Herbicide treatments used for pine culture are not appropriate for Eucalyptus plantations and new treatments must be developed to ensure adequate control of competing vegetation without seedling damage.

Invasiveness. Potential invasiveness was the key concern addressed at the conference and three papers in this special issue look at this from different perspectives. T. H. Booth brings a broad perspective from Australia and other countries, particularly the potential for invasiveness in frost-prone regions. D. R. Gordon et al. apply the Australian Weed Risk Assessment tool that is based on traits associated with invasiveness and experience from other countries. M. A. Callaham et al. report on a preliminary field assessment of actual escapes from Eucalyptus plantings in South Carolina and Florida. Some Eucalyptus species have biological properties that could result in invasiveness in some locations. Globally, only eight eucalypt species are considered to be invasive in some locations: Corymbia maculata, E. camaldulensis, E. cinerea, E. cladocalyx, E. conferruminata, E. globulus, E. grandis, and E. robusta [6]. A review of general experience of Eucalyptus around the world (e.g., Brazil, Chile, and Australia) and the experience from regions similar to the Lower Coastal Plain (e.g., China and Brazil) concluded that the potential for Eucalyptus invasiveness is generally low due to poor dispersal, small seeds with limited viability that require bare soil to germinate, and light demanding seedlings that do not grow successfully under closed forest or understory canopies. However, Eucalyptus invasiveness has been a particular problem in southern Africa, where it was initially introduced around 1828 and was widely planted from about 1850, more than 50 years before they were introduced into Brazil. E. camaldulensis is a particularly serious problem in southern Africa as it has spread down watercourses as it does naturally in Australia. It appears that the more commonly cultivated a species is, the more likely it is to become invasive, in accord with the theoretical requirement of sufficient propagule pressure before invasiveness becomes apparent.

Weed risk assessment tools based on qualitative scores that depend on biological properties and confirmed invasiveness or naturalization in one or more locations could be useful as a screening tool. High scores indicate potential for invasiveness and a need for further study in context of an overall assessment of a species' potential benefits and risks as a short-rotation woody crop. D. R. Gordon et al. selected 38 Eucalyptus taxa (species, hybrids, or clones) that had previously been evaluated using the Australian Weed Risk Assessment tool in Hawaii, the Pacific, or Florida; they found the four taxa that are currently most likely to be cultivated in the USA South (E. amplifolia, E. benthamii, E. dunnii, and E. dorrigoensis) to be low invasion risks. Two taxa, E. camaldulensis and E. viminalis, were assessed as high risks and there were two taxa needing further evaluation (E. macarthurii and E. urograndis). Three other taxa that have received attention are predicted to pose a high risk of invasion (E. grandis, E. robusta, and E. saligna). All the scores in D. R. Gordon et al. were higher than those found by earlier assessments.

In the study reported by M. A. Callaham et al., Eucalyptus invasiveness potential in the southeastern USA was assessed based on an analysis of seedlings found within and near 
established plantations on 3 sites in South Carolina and 16 sites in Florida. They found a small number of Eucalyptus seedlings growing in areas adjacent to established plantings in Florida where seedlings were found within and nearby to Eucalyptus plantations at 4 sites, but only two individuals were detected more than $45 \mathrm{~m}$ from plantation boundaries. All seedlings were E. amplifolia, E. robusta, or E. grandis. Their results indicated that some Eucalyptus species may naturalize (spontaneously reproduce in their introduced range) in the South but there was no evidence for invasion (reproducing and spreading long distances, i.e., 100s of $\mathrm{m}$ in large numbers). Surrounding intensively managed land use seemed to militate against escape; no seedlings were found in agricultural, suburban, or citrus orchard land uses. Because seedlings were found in less intensively managed areas such as partially wooded sites, they cautioned that the potential for spread into unmanaged areas should not be dismissed.

Overall, these papers indicated a limited potential for invasiveness of most Eucalyptus species under consideration for planting in frost-prone areas outside of Peninsular Florida. However, the risk of invasiveness associated with Eucalyptus may increase as the scale of culture and propagule pressure increases in the southern USA. One factor put forth to explain the limited spread of Eucalyptus in subtropical climates may be that the fungal symbionts of the species in question are not able to fruit and disperse into the surrounding soils. Another paper by M. Ducousso et al. in this special issue, however, points out that in Africa and Madagascar, diverse species of ectomycorrhizal fungi are found under Eucalyptus even though intentional inoculation has been limited to a few experimental trials.

These authors provide suggestions for avoiding or managing potential invasiveness. Keeping plantations away from watercourses and maintaining clear firebreaks should reduce the chances of escape from plantations. Interspersing Eucalyptus plantations with other intensive land uses such as pine plantations would limit the ability of Eucalyptus to spread and establish. Planting sterile genotypes or clones selected for low levels of seed production or even modified for sterility could reduce the risk of invasiveness. Short rotations reduce total flower production potential of individual trees and stands and reduce the total number of heavy seed production years. Short rotations are also characterized by intensive establishment practices that would limit the potential for individuals to naturalize. But whatever genotypes are grown (whether genetically modified organisms, clones, or otherwise), new plantations should be carefully monitored to check on seed production and ensure that the trees are not invasive. Over time, continued vigilance and robust monitoring will be needed because invasiveness potential may increase due to increased propagule pressure, climatic changes that remove current barriers to reproduction such as lack of synchrony between flowering and pollinators, and short-term evolution and hybridization that may alter plant traits and increase invasive potential.

Fire Risk. S. L. Goodrick et al. in this issue sought to answer two questions regarding the potential fire risk of widespread plantings of Eucalyptus in the Lower Coastal Plain: (1) what effect would this have on risk of wildfires? and (2) how would fire behavior in Eucalyptus stands differ from fires in commonly occurring vegetation types such as pine plantations? They provide preliminary answers to these questions based on modeling using the Fuel Characteristic Classification System (FCCS) and literature values for fuel characteristics and loads. They found that surface fire behavior in young Eucalyptus plantations differs little from surface fires in fuels common to pine forests characteristic of the Lower Coastal Plain. Eucalyptus is better known, however, for its crown fires and spotting behavior. The FCCS modeled crown fire potential well but existing models do not adequately account for potential spotting behavior of Eucalyptus. Modeling suggests that fire behavior at the stand level differs little from current conditions and points to the importance of avoiding the development of a shrub layer. Stands managed on short rotation (less than 10 years) will likely be harvested before bark shedding presents a significant spotting problem. Fire risk will likely vary with the landscape context of Eucalyptus plantations. Internationally, fires are more likely to start outside Eucalyptus plantations than inside but once a crown fire is initiated, it will spread rapidly and the potential is for more severe crown fire behavior than in pine stands. These authors recommend that future work focus on possible effects on fire risk in the landscape. As it becomes clear which species have the greatest commercial potential for widespread planting, it will be possible to better predict spotting potential and evaluate applicability of available models of firebrand production and dispersal to current and future conditions in the Lower Coastal Plain, keeping in mind the variability in wood properties of clones as noted in another paper in this issue by B. L. C. Pereira et al.

Water Use. Water use of Eucalyptus is a controversial issue, and many studies have been directed toward water use at the individual tree and stand levels with fewer studies at the landscape (catchment or watershed) level. In this special issue, J. M. Albaugh et al. review the techniques used to quantify water use of Eucalyptus plantations, provide an overview of studies in water-limited South Africa, and recommend where to concentrate future research efforts. In South Africa, WUE varies significantly among Eucalyptus clones and is not a constant characteristic of a given genotype; WUE for Eucalyptus species in South Africa ranged from 0.0008 to $0.0123 \mathrm{~m}^{3}$ of stemwood produced per $\mathrm{m}^{3}$ water consumed. W. Dvorak [7] recently reviewed studies internationally and applied this experience to understanding potential effects of planting Eucalyptus in the southern USA. Physiological studies in several countries has shown that Eucalyptus have similar water use efficiency (WUE) to other tree species. Water consumption at the stand level depends upon water availability, vapor pressure deficit, and WUE; water availability, therefore, is a major determinant of productivity [7].

Actual water use by Eucalyptus in a watershed depends on many factors including the areal extent, size, spatial distribution, productivity, and age-class distribution of planted stands. Much has been made of the effect of converting other land uses to Eucalyptus plantations. Eucalyptus has potentially higher water use and water use efficiency compared to 
pasture, pine plantations, and native forests but water use is much lower in Eucalyptus plantings than in irrigated crops. Studies in other countries suggest that effects of Eucalyptus plantations on stream flow may be most apparent in drier regions where precipitation is approximately equal to evapotranspiration (this point was effectively made by Walter de Paula Lima, University of São Paulo, in his talk at the conference on Hydrology studies of Eucalyptus in Brazil). Water consumption by Eucalyptus plantations will be higher in terms of percentage of water supply in drier regions but absolute water consumption will be higher in wetter region [7].

Information about resource requirements (water uptake and nutrient requirements) and resource use and production efficiencies of Eucalyptus trees and plantations, as well as stand-level measures of water quality across a range of sites, could inform landscape models. The key indicator of plantation sustainability is water balance in a watershed, not just evapotranspiration or consumption [7]. Ongoing modeling studies suggest that predicted watershed-level response to small and moderate amounts of land in Eucalyptus plantations in the southern USA may be difficult to detect. Key information needs are the potential influence of Eucalyptus plantations on isolated wetlands and potential impacts of different tree densities on hydrology. Management strategies to avoid water quantity and quality impacts include avoiding planting Eucalyptus in recharge areas and other hydrologically sensitive areas, longer rotations or lower densities, and adherence to water quality best management practices. Under current climatic and land-use conditions, the Lower Coastal Plain presents no apparent limitations to Eucalyptus plantations from a water standpoint [8]. The variability in WUE among Eucalyptus clones suggests a potential for breeding trees with improved WUE and drought resistance [7] which could be important under future climate and land uses that compete with forestry for available water [8].

Sustainability. Eucalyptus plantations in countries outside the USA are managed under the auspices of sustainable forestry certification programs, and significant variation among Eucalyptus species severely limits generalizations that can be made concerning environmental issues associated with establishing and managing Eucalyptus plantations. Environmental issues associated with use of Eucalyptus species as short-rotation woody crops in the USA South appear to be manageable with risk-appropriate strategies but merit ongoing, substantive attention and investigation. Indicators, including those related to biodiversity, are needed to support assessment of both environmental and socioeconomic sustainability of bioenergy systems, including culture of Eucalyptus. Existing indicators proposed in the scientific literature and developed by other entities could potentially be adapted for application to Eucalyptus culture in the southern US, as discussed in this special issue by V. H. Dale et al. and X. Huang et al. Studies outside the southern USA confirm that Eucalyptus forests are not "green deserts" and do support native plant and animal species. Studies of short-rotation woody crops in the USA suggest that some native plant and animal species will respond positively and others negatively to Eucalyptus plantations. Interpretation of results from studies of biodiversity response to Eucalyptus plantations will likely depend in part on the experimental comparison (e.g., agricultural land, pine plantations, mature hardwood forest, or comparable-age native hardwood forests).

Existing information about Eucalyptus culture from other countries may serve as a strong basis for hypotheses about environmental issues associated with culture of this genus in the southern USA. Environmental implications of Eucalyptus culture should be considered in the context of those associated with alternatives for fiber and energy production. V. H. Dale et al. selected a suite of 35 sustainability indicators, including 19 environmental (in areas of soil quality, water quality and quantity, greenhouse gases, biodiversity, air quality, and productivity) and 16 socioeconomic (social wellbeing, energy security, trade, profitability, resource conservation, and social acceptability) indicators. They found that some requisite information was lacking at the needed temporal and spatial scales in order to assess the potential for a successful bioenergy industry based on Eucalyptus. Nevertheless, they concluded that the sustainability issues did not differ greatly from those of other feedstocks and it is the specifics of how the industry is developed and deployed that determine environmental implications.

Economic and sociopolitical factors will heavily influence the nature of Eucalyptus culture in the southern USA. X. Huang et al. reported on a geospatial method called BioSAT (Biomass Site Assessment Tool) to identify interactions associated with landscape features, socioeconomic conditions, and ownership patterns and the influence of these variables on locating potential conversion facilities. They applied this method to estimate opportunity zones for woody cellulosic feedstock based on landscape suitability and market competition for the resource. Using a landscape competition index, they identified potential opportunity zones in central Mississippi, northern Arkansas, south central Alabama, southwest Georgia, southeast Oklahoma, southwest Kentucky, and northwest Tennessee. Their method was not specific to Eucalyptus; however it could be adapted by limiting the study area to the suitable region for frost-tolerant clones. Even though decisions about establishing Eucalyptus plantations on private land can be based on narrow economic considerations, enlightened management and certification requirements increasingly recognize the necessity of public input. Multistakeholder biodiversity conservation initiatives such as The Forest Dialogue for the Atlantic Forest, The Atlantic Forest Restoration Pact, and the Sustainable Forest Mosaics Project may serve as models for conservation planning related to Eucalyptus culture in the southern USA.

\section{John A. Stanturf \\ Eric D. Vance \\ Thomas R. Fox \\ Matias Kirst}

\section{References}

[1] DOE, U.S. Billion Ton Update: Biomass Supply For a Bioenergy and Bioproducts Industry, Oak Ridge National Laboratory, Oak Ridge, Tenn, USA, 2011. 
[2] D. Dougherty and J. Wright, "Silviculture and economic evaluation of eucalypt plantations in the Southern US," BioResources, vol. 7, no. 2, pp. 1994-2001, 2012.

[3] R.S. Zalesny Jr. et al., "Woody biomass from short rotation energy crops," in Sustainable Production of Fuels, Chemicals, and Fibers From Forest Biomass, J. Y. Zhu, X. Zhang, and J. Pan, Eds., pp. 27-63, American Chemical Society, Washington, DC, USA, 2011.

[4] M. Hinchee, W. Rottmann, L. Mullinax et al., "Short-rotation woody crops for bioenergy and biofuels applications," In Vitro Cellular and Developmental Biology, vol. 45, no. 6, pp. 619-629, 2009.

[5] R. Gonzalez, T. Treasure, J. Wright et al., "Exploring the potential of Eucalyptus for energy production in the Southern United States: financial analysis of delivered biomass. Part I," Biomass and Bioenergy, vol. 35, no. 2, pp. 755-766, 2011.

[6] M. Rejmánek and D. M. Richardson, "Eucalypts," in Encyclopedia of Biological Invasions, D. Simberloff and M. Rejmánek, Eds., pp. 203-209, University of California Press, Berkeley, Calif, USA, 2011.

[7] W. Dvorak, "Water use in plantations of Eucalypts and pines: a discussion paper from a tree breeding perspective," International Forestry Review, vol. 14, no. 1, pp. 110-119, 2012.

[8] G. Sun, S. G. McNulty, J. A. Moore Myers, and E. C. Cohen, "Impacts of multiple stresses on water demand and supply across the southeastern United States," Journal of the American Water Resources Association, vol. 44, no. 6, pp. 1441-1457, 2008. 

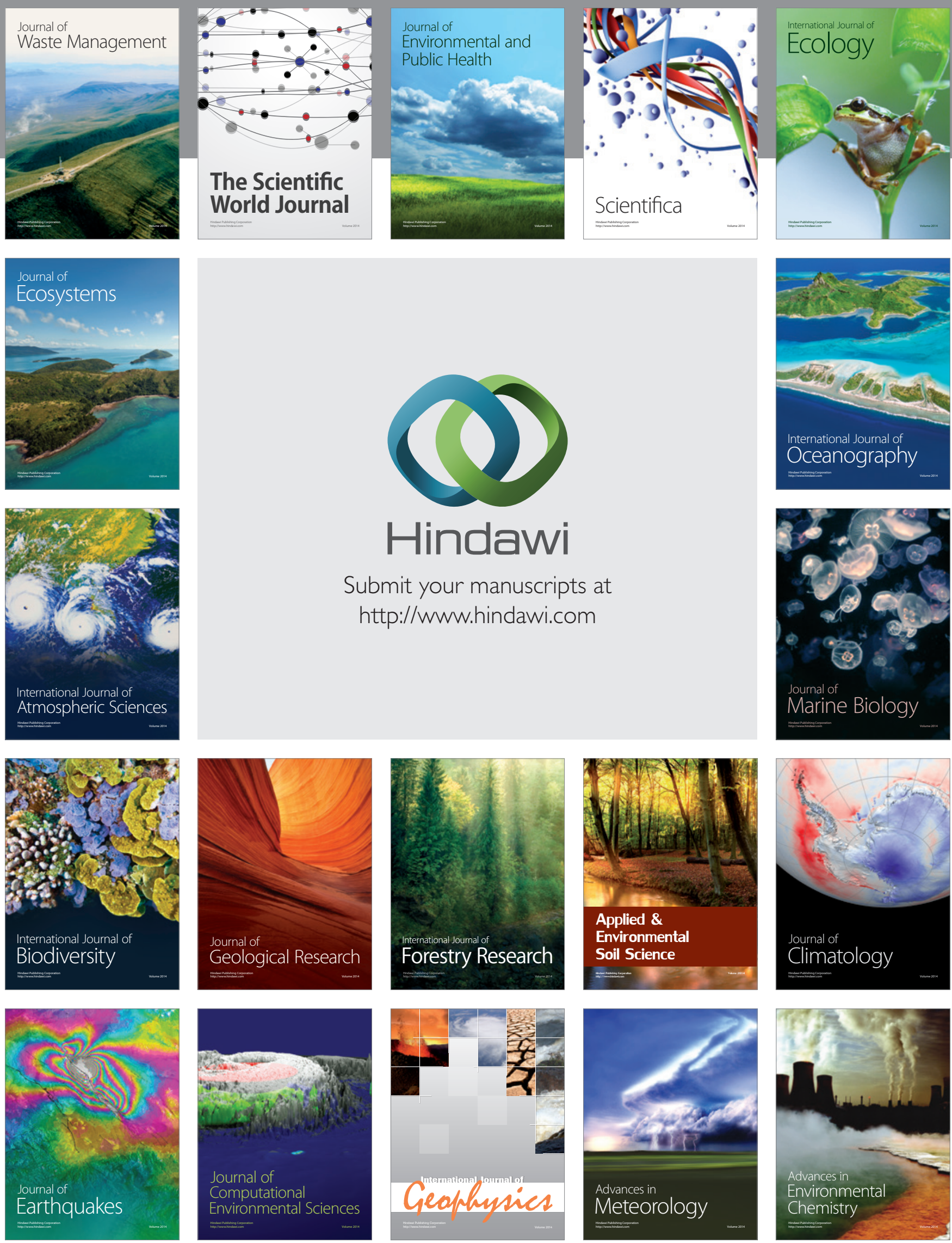